\title{
Study on Purification Effect of Artificial Wetland on Micro-polluted River
}

\author{
Zhao Changheng, Cha Fengjuan, Le Yongzhi, Zhou Guangsheng, Qian Liping* \\ College of Life and Environmental Sciences, Huangshan University, Huangshan 245041, China
}

\begin{abstract}
The research on the purification effect of artificial wetland on micro-polluted river and the detection of aquatic plants showed that TP, TN, NH3-N and COD in river were significantly lower than those in untreated river, indicating that the artificial wetland has a good purification effect on these water quality indicators; Testing from different wetland types, it can be seen that the effect of removing TP, TN, NH3-N and other factors in the subsurface wetland is the best, and the artificial surface wetland is second, while the effect of removing COD factor it is close to that of artificial surface wetland. As for the effect of removing pollution factors in artificial wetlands in different seasons, it can be drawn frow the test that the removal rate of TP and TN in artificial wetlands in different seasons can be obtained: wet season $>$ normal season > dry season; and the removal rate of NH3-N and COD is normal season $>$ dry season $>$ wet season. In addition to the TN factor, the water quality during the dry season and normal season is significantly better than that during the wet season. Based on the analysis of the total amount of heavy metals absorbed by three kinds of aquatic plants, it can be concluded that different plant has different effect of removing TN and TP.
\end{abstract}

\section{Introduction}

With the development of society, a large amount of industrial wastewater and domestic sewage are generated, which leads to the water pollution. According to relevant statistics, China's annual sewage discharge amount is more than 40 billion tons ${ }^{[1]}$, many rivers are directly discharged without purification treatment ${ }^{[2]}$, and industrial wastewater is more harmful to rivers, so it is of great practical significance to purify water more effectively and improve the efficiency of water use ${ }^{[3]}$.

Artificial wetlands are a natural system built for the natural simulation of sewage treatment. It is a kind of a packed bed which is artificially laid for sewage treatment with a certain aspect ratio and bottom slope pressing soil and filler, in which are planted some aquatic plants with good function, high survival rate, long growth period, beautiful appearance and economic value, such as: cedar, Phragmites communis (Cav.), Alisma plantago-aquatica L., Canna indica L. and pupa, etc.,so that a unique animal and plant ecosystem is formed through a series of biological and chemical physical processes to purify the water ${ }^{[4]}$. For artificial wetlands, the bottom of the wetland is filled with gravel-filled matrix, which not only fully adsorbs the water, but also creates conditions for microbial growth ${ }^{[5]}$. At the same time, the aquatic plants in the "adsorbed pollutants" can also provide nutrients and oxygen for the growth of microorganisms, and the microbial pollutants such as nitrogen nutrients can be absorbed and utilized, and the polluted wastewater can be effectively treated under various actions [6]. Artificial wetland vegetation and substrate directly play a role in filtering pollutants during the purification process ${ }^{[7]}$. At the same time, different wetland vegetation and filler matrices are often used according to different wastewater operations, which produces different types of artificial wetlands ${ }^{[8]}$.

With the artificial wetland in Shuixi river in Huangshan University as the research object, the author studied the water quality standard and the content of different heavy metals in the plants, evaluated the water quality of the artificial wetland, and analyzed the enrichment of heavy metals by different plants in the artificial wetland in order to provide a reference for improving the water treatment effect of artificial wetlands.

\section{Materials and methods}

\subsection{Overview of the study area}

As a tributary of Shuaishui river, Shuixi River flows through the the artificial wetland in the campus of Huangshan University. The artificial wetland covers an area of $7,500 \mathrm{~m}^{2}$, and the flow rate of the treated river water is $2,100 \mathrm{~m}^{3} / \mathrm{d}$. The artificial wetland in Shuixi River consists of a primary oxidation pond, horizontal subsurface artificial wetland, free surface artificial wetland and secondary oxidation pond. The basic overview is as follows:

\footnotetext{
* Corresponding author: lpq@hsu.edu.cn
} 
(1) Primary oxidation pond

The area of the first oxidation pond covers $1500 \mathrm{~m}^{2}$, and the average water depth is $0.8 \mathrm{~m}$, with $13.71 \mathrm{~h}$ residence time. Some aquatic plants are planted in the pond, such as: Alisma plantago-aquatica L. and Canna indica L., mushroom grass, yellow iris, lycopodium, water onion, water lily, etc., and artificial islands are also built in the pond with $30 \%$ coverage of aquatic plants. The main function of the primary oxidation pond is to regulate the water quality and quantity, purify the micro-polluted river and reduce the processing load of the artificial wetland.

(2) Horizontal subsurface artificial wetland

The length and width of subsurface artificial wetland is $30 \mathrm{~m}$ and $35 \mathrm{~m}$, covering the area of $1000 \mathrm{~m}^{2}$, and the water depth is $1 \mathrm{~m}$ with $0.1 \%$ bottom slope and $11.45 \mathrm{~h}$ residence time. The bottom layer is made of gravel and sands, the middle layer is made of fine stones, and the upper layer is made of ceramsite and other materials. The plants on the surface of the submerged wetland are Alisma plantago-aquatica L. and Canna indica L., and Phragmites communis (Cav.), with a 95\% coverage. The fillers and plant roots are used to absorb pollutants in river to achieve the purpose of purifying water.

(3) Free surface artificial wetland

The process of treating sewage by free surface artificial wetland is to form a water flow on the surface of the wetland and slowly advance by pushing flow. The area covers $3500 \mathrm{~m}^{2}$ with $0.1 \%$ bottom slope, and the residence time is $20 \mathrm{~h}$ with $0.5 \mathrm{~m}$ water depth. There are a large number of aquatic plants such as floating plants, emergent plants, tall trees and cedars in the wetlands, and the plant coverage is $80 \%$.

(4) Secondary oxidation pond

The area of the secondary oxidation pond covers $1500 \mathrm{~m}^{2}$, the water depth is $0.8 \mathrm{~m}$, and the micro-polluted river water residence time is $13.71 \mathrm{~h}$. The aquatic plants in the pond have biological filters formed by roots such as lycopene and Phragmites communis (Cav.) to intercept pollutants in the river, thereby achieving the purpose of improving water quality.

\section{2 sampling point layout and collection}

The Shuixihe artificial wetland presents a multi-level, multi-system, and irregular distribution, all of which are connected by flowing water. Since the depth of the water is basically below $1 \mathrm{~m}$, at the end of each function area, samples are taken at a water surface of $0.3-0.5 \mathrm{~m}$. The sampling points are shown in Figure-1. According to Figure 1, the first point is the inlet of the artificial wetland, the second sampling point is the inlet of the subsurface wetland, the third sampling point is the outlet of the subsurface wetland, the inlet of the surface wetland, and the fourth sampling point is the outlet of the surface wetland. The removal rate of the wetland water outlet was calculated by measuring the total nitrogen
$(\mathrm{TN})$, total phosphorus $(\mathrm{TP})$, nitrogen nitrogen (NH3-N) and chemical oxygen demand (COD) contents at the four sampling points.

In order to avoid the impact of rain on the water quality of the wetland, every time sampling is not collected on raining days. The collected water sample should be placed in a $550 \mathrm{~mL}$ polyethylene bottle, then the sulfuric acid reagent should be added, the water sample should be adjusted to $\mathrm{pH} \leq 1$, sealed and brought back to the laboratory, and stored in a refrigerator at about $4{ }^{\circ} \mathrm{C}$. The sampling frequency is twice a month for it takes a certain amount of time since the waterflow completely flows from one area to the next. Therefore, on the first day of the experiment, the water sample at the first point was collected in the morning, the second point in the afternoon, and the third point was collected the next morning, the fourth point in the morning on the third day. The sampling period is from December 2017 to November 2018. At the same time, it is set that December, January and February are dry season, March, April, October and November are normal season, and May, September is wet season.

In October, November, 2017 and June 2018, three kinds of emergent plants (Phragmites communis (Cav.), Alisma plantago-aquatica L. and Canna indica L.) were selected in the subsurface and surface wetland. The sample was collected by diagonal sampling with the location $1.5 \mathrm{~m}$ away from the edge. Each of the three plants mentioned above was collected in different areas for 3 times in sunny days. The manual extraction method was used. After the extraction, the plants were kept separately to prevent nutrient operation and brought back to the lab.

\subsection{Measurement items and methods}

The water quality of TN, TP, NH3-N and COD contents in the artificial wetland were measured in time after each water sample collection. The content of $\mathrm{TN}$ was measured by alkaline potassium persulfate digestion ultraviolet spectrophotometry; the content of COD dichromate method; the content of NH3-N Nessler reagent spectrophotometry and the content of TP ammonium molybdate spectrophotometry. All of the above are carried out in accordance with the methods specified in the Water and Wastewater Monitoring and Analysis Methods (Fourth Edition). The plant samples collected each time were subjected to $\mathrm{H} 2 \mathrm{SO} 4-\mathrm{H} 2 \mathrm{O} 2$ digestion to measure the heavy metal content by atomic absorption method.

\section{Data and analysis}

\subsection{Water detection data and analysis}

\subsubsection{TP data and analysis}


Table 1 Content of TP in different types of wetlands in different season (mean value) unit(mg/L)

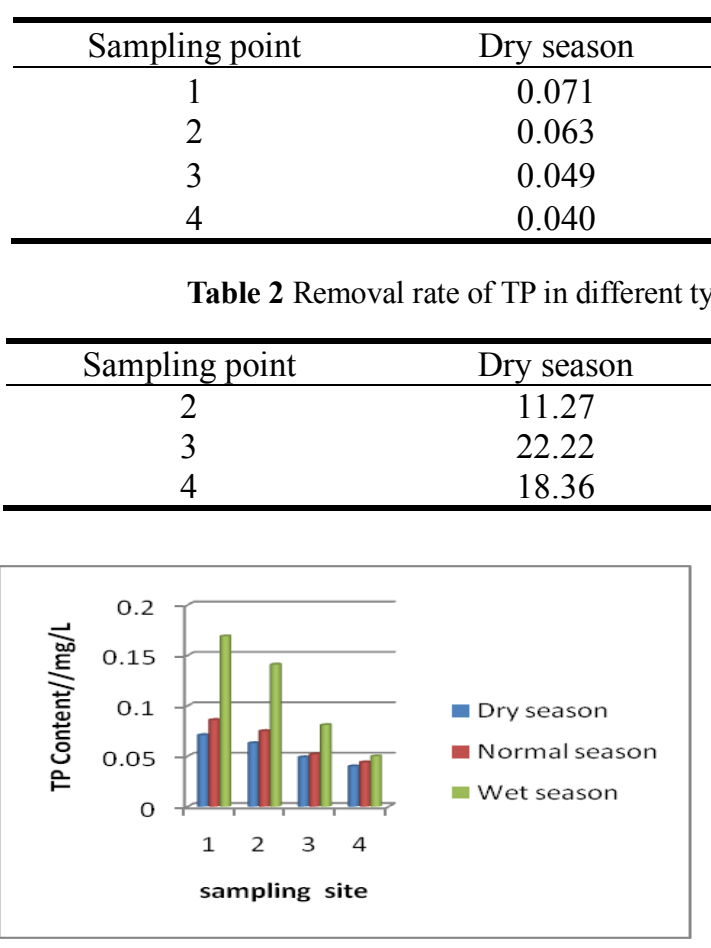

Figure 1 Content of TP in different types of wetlands in different season (mean value)

It can be seen from Table 1 that in dry season, normal season and wet season, the TP concentration at point 1 is higher than the TP concentration at point 4 , indicating that the artificial wetland system has a certain ability to remove TP from domestic sewage. It can be seen from Tables 1 and 2 that the average removal rates of different types of artificial wetlands in different seasons are $13.54 \%$ for primary oxidation ponds, $31.81 \%$ for subsurface wetlands, and $24.00 \%$ for surface wetlands; and removal rates for different seasons are as the following: dry season is $43.67 \%$, normal season $48.85 \%$,

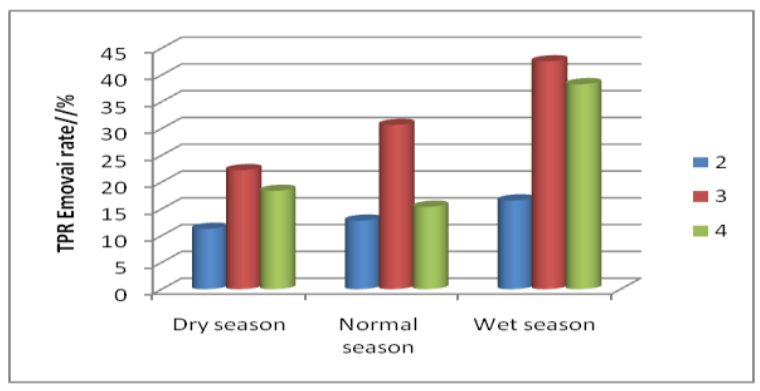

Figure 2 Removal rate of TP in different types of wetlands

and wet season is $70.41 \%$. Through comprehensive analysis it can be drawn that the removal effect should be artificial subsurface wetland $>$ surface wetland $>$ first-grade oxidation pond; while as for the season it should be wet season $>$ normal season $>$ dry season.

In addition to the purification effect of the wetland itself during the wet season, there is also a large amount of water during the wet season, so the dilution effect is strong, which also reduces the amount of pollutants in the water.

\subsubsection{TN data and analysis}

Table 1 Content of TN in different types of wetlands in different season (mean value) unit(mg/L)

\begin{tabular}{|c|c|c|c|}
\hline Sampling point & Dry season & Normal season & Wet season \\
\hline 1 & 0.474 & 0.690 & 1.156 \\
\hline 2 & 0.470 & 0.570 & 0.892 \\
\hline 3 & 0.461 & 0.430 & 0.620 \\
\hline 4 & 0.456 & 0.340 & 0.446 \\
\hline \multicolumn{4}{|c|}{ Table 2 Removal rate of TN in different types of wetlands } \\
\hline Sampling point & Dry season & Normal season & Wet season \\
\hline 2 & 0.84 & 17.39 & 22.84 \\
\hline 3 & 1.91 & 24.56 & 30.49 \\
\hline 4 & 1.08 & 20.9 & 28.06 \\
\hline
\end{tabular}




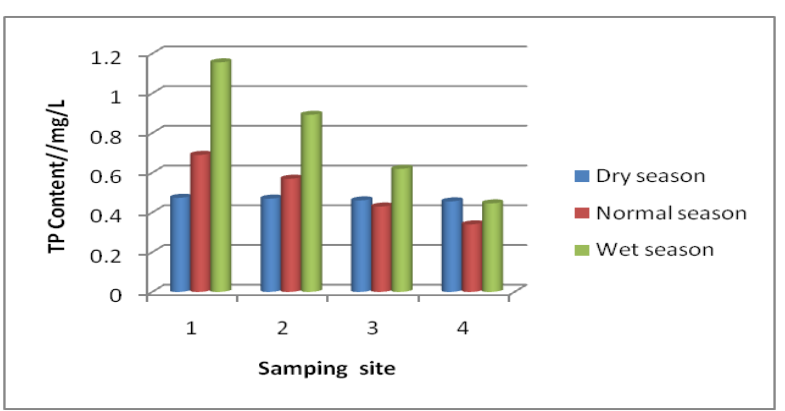

Figure 3 Content of TN in different types of wetlands (mean value)

Based on Tables 3 and 4 above, the average removal rates of different types of artificial wetlands in different seasons are as the following: $13.69 \%$ for primary oxidation ponds, $18.99 \%$ for subsurface wetlands, and $16.68 \%$ for surface wetlands; removal rates at different seasons are as the following: $3.80 \%$ in dry season, $50.72 \%$ in normal season, and $61.42 \%$ in wet season. Through comprehensive analysis it can be drawn that as for the removal effect, artificial subsurface wetland $>$ surface wetland $>$ first-grade oxidation pond; while as for the season it should be wet season $>$ normal season $>$ dry season.

In dry season, the denitrification effect of the artificial wetland on the river is not obvious, and the denitrification effect is better in normal season and wet season. The extremely low removal rate of wetlands

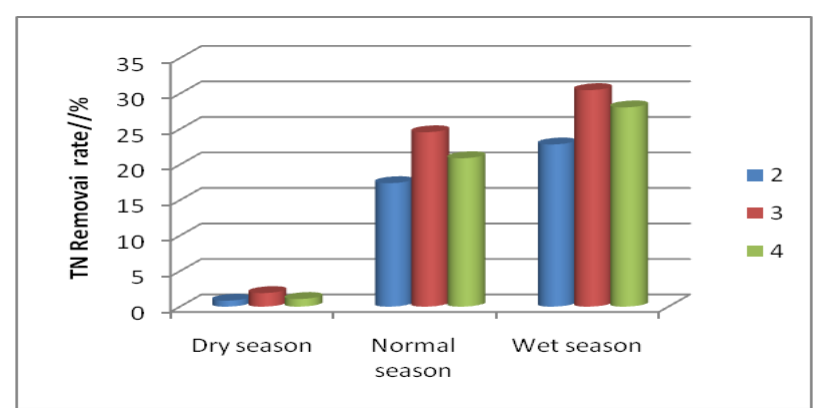

Figure 4 Removal rate of TN in different types of wetlands in different season

during dry season may be caused by cold weather, plants in dormant state, and low activity of microorganisms; the absorption of plants, adsorption of filler matrix and nitrification-denitrification can remove the nitrogen in the micro-polluted river. The high temperature during the normal season and wet season and strong microbial activity make the nitrification-denitrification obvious. The structure of the artificial subsurface wetland makes the interior of the wetland present anaerobic state, which is beneficial to the nitrification-denitrification reaction. Denitrification is the denitrifying bacteria that convert $\mathrm{NO} 3$ into N2 under anoxic conditions and run out of the water ${ }^{[9]}$.

\subsubsection{NH3-N data and analysis}

Table 5 Content of NH3-N in different types of wetlands in different season (mean value) unit(mg/L)

\begin{tabular}{cccc}
\hline Sampling point & Dry season & Normal season & Wet season \\
\hline 1 & 0.601 & 0.772 & 0.701 \\
2 & 0,525 & 0.606 & 0.629 \\
3 & 0.432 & 0.445 & 0.516 \\
4 & 0.363 & 0.342 & 0.432 \\
\hline
\end{tabular}

Table 6 Removal rate of NH3-N in different types of wetlands unit \%

\begin{tabular}{cccc}
\hline Sampling point & Dry season & Normal season & Wet season \\
\hline 2 & 12.64 & 21.50 & 10.27 \\
3 & 17.71 & 26.57 & 17.97 \\
4 & 15.97 & 23.15 & 16.28 \\
\hline
\end{tabular}

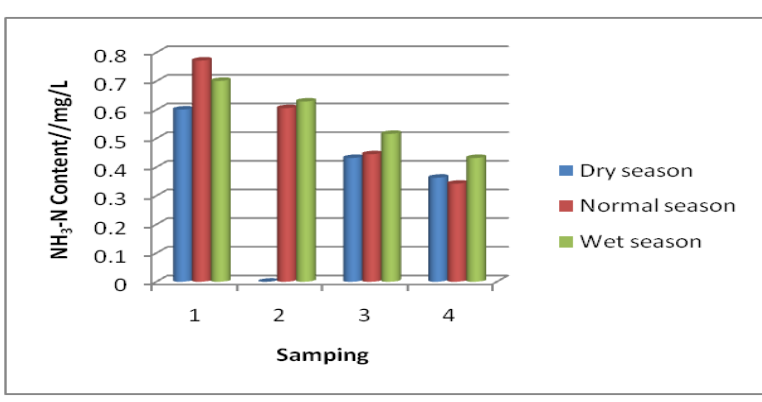

Figure 5 Content of NH3-N in different types of wetlands (mean value)

The ammonia nitrogen in Shuixi River mainly comes from rural domestic sewage and agricultural waste water. It can be concluded from Tables 5 and 6 that the average removal rates of different types of artificial wetlands in

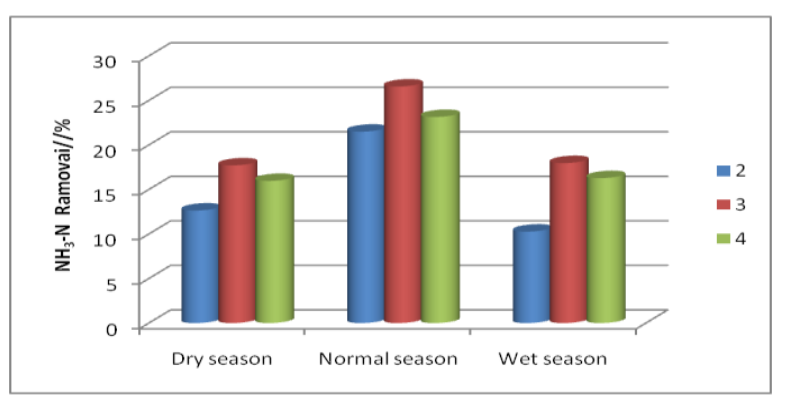

Figure 6 Removal rate of NH3-N in different types of wetlands in different season

different seasons are: $14.80 \%$ for primary oxidation ponds, $20.75 \%$ for subsurface wetlands, and $18.47 \%$ for surface wetlands; and removal rates for different seasons are: dry season $39.60 \%$, normal season $55.70 \%$, wet 
season $38.37 \%$. Through comprehensive analysis it can be concluded that as for the removal effect, artificial subsurface wetland $>$ surface wetland $>$ first-grade oxidation pond; while as for the season it should be normal season $>$ dry season $>$ wet season.

The removal of ammonia nitrogen in artificial wetlands is mainly through the action of nitrifying bacteria and denitrifying bacteria, as well as the adsorption of fillers. In normal season, the water volume and the water flow speed are relatively moderate, and the residence time of the river in the wetland is relatively long. At this time, the microorganisms have a good effect on the purification of ammonia nitrogen. In wet season, the large water volume, the fast water flow and the insufficient residence time of the river in the artificial wetland result in the purification ability being worse than normal season and dry season.

\subsubsection{COD data and analysis}

unit(mg/L)

\begin{tabular}{cccc}
\hline Sampling point & Dry season & Normal season & Wet season \\
\hline 1 & 22.32 & 35.46 & 39.68 \\
2 & 19.02 & 28.6 & 33.36 \\
3 & 15.01 & 20.5 & 25.58 \\
4 & 10.49 & 15.5 & 20.02 \\
\hline
\end{tabular}

Table 8 Removal rate of COD in different types of wetlands

unit $\%$

\begin{tabular}{cccc}
\hline Sampling point & Dry season & Normal season & Wet season \\
\hline 2 & 14.15 & 19.34 & 15.93 \\
3 & 21.08 & 28.32 & 23.32 \\
4 & 30.11 & 24.39 & 21.74 \\
\hline
\end{tabular}

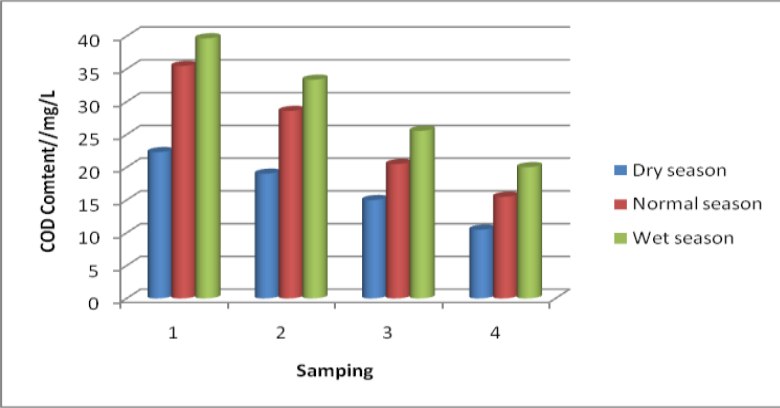

Figure 7 Content of COD in different types of wetlands season (mean value)

It can be seen from Tables 7 and 8 that the average removal rates of different types of artificial wetlands in different seasons are $16.47 \%$ for primary oxidation ponds, $24.24 \%$ for subsurface wetlands, and $25.41 \%$ for surface wetlands; the removal rates in different seasons are $53.00 \%$ for dry season, $56.29 \%$ for normal season, and $49.55 \%$ for wet season. Through comprehensive analysis it can be concluded that as for the removal effect: surface wetland $>$ artificial subsurface wetland $>$ primary oxidation pond; while as for the season it should be normal season $>$ dry season $>$ wet season.

The micro-polluted water flow removes the soluble organic pollutants in the sewage through the adsorption, absorption and metabolism degradation of the biofilm at the root of the plant, thereby reducing the COD concentration in the river, while the relatively insoluble organic pollutants in the sewage after filtration and

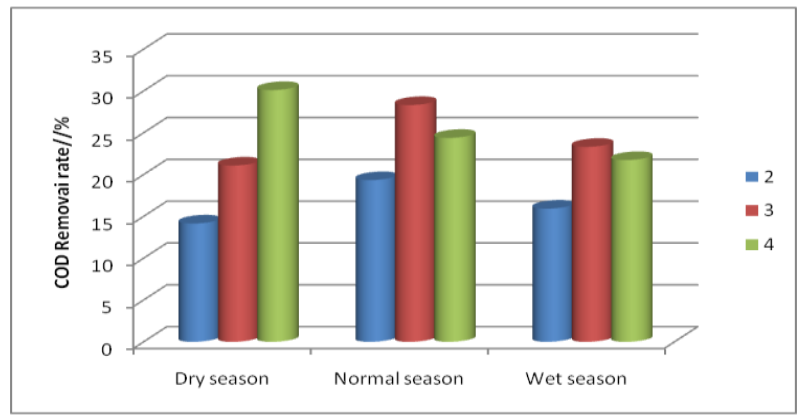

Figure 8 Removal rate of COD in different types of wetlands in different

precipitation by the matrix, it is quickly intercepted and then degraded by the absorption of microorganisms. The process of microbial degradation of organic matter is divided into aerobic and anaerobic degradation. Of course, plants can also play a more significant role in the process, and the presence of plants can accelerate the mineralization process and humification process of microorganisms to organic matter ${ }^{[10]}$. The plant itself can absorb some of the organic pollutants, and the root microorganisms of the plant can accelerate the decomposition of organic pollutants ${ }^{[11]}$.

\subsection{Aquatic plant detection data and analysis}

\subsubsection{Analysis of the content of heavy metals in aquatic plants}

Table 9 Total enrichment of heavy metals by aquatic plants

Unit $\mathrm{mg} / \mathrm{g}$

\begin{tabular}{|c|c|c|c|}
\hline \multirow[t]{2}{*}{ Variety } & $\begin{array}{l}\text { Phragmites communis } \\
\text { (Cav.) Trin. ex Steud. }\end{array}$ & $\begin{array}{l}\text { Alisma plantago-aquatica } L \text {. } \\
\text { plantago-aquatica } \mathrm{L} \text {. }\end{array}$ & Canna indica L. indica L. \\
\hline & Root & Root & Root \\
\hline
\end{tabular}




\begin{tabular}{lllllll}
\hline $\mathrm{Cd}$ & 0.039 & 0.0072 & 0.0464 & 0.0441 & 0.0592 & 0.0460 \\
$\mathrm{Cu}$ & 0.0265 & 0.0113 & 0.0361 & 0.0305 & 0.0409 & 0.0309 \\
$\mathrm{~Pb}$ & 0.1891 & 0.1416 & 0.1712 & 0.1675 & 0.1858 & 0.1545 \\
$\mathrm{Zn}$ & 0.2194 & 0.0279 & 0.2577 & 0.1265 & 0.3620 & 0.1673 \\
\hline
\end{tabular}

Table 10 Enrichment of heavy metals in different parts of aquatic plants

Unit $\mathrm{mg} / \mathrm{g}$

\begin{tabular}{ccccc}
\hline Variety & $\begin{array}{c}\text { Phragmites } \\
\text { communis (Cav.) } \\
\text { Trin. ex Steud. }\end{array}$ & $\begin{array}{c}\text { Alisma } \\
\text { plantago-aquatica } \text { L. } \\
\text { plantago-aquatica } \text { L. }\end{array}$ & $\begin{array}{c}\text { Canna indica L. } \\
\text { Indica } \text { L. }\end{array}$ & Total \\
\hline $\mathrm{Cd}$ & 0.0461 & 0.0905 & 0.1053 & 0.2419 \\
$\mathrm{Cu}$ & 0.0378 & 0.0666 & 0.0718 & 0.1762 \\
$\mathrm{~Pb}$ & 0.3307 & 0.3386 & 0.3403 & 1.0096 \\
$\mathrm{Zn}$ & 0.2474 & 0.3842 & 0.5293 & 1.1609 \\
\hline
\end{tabular}

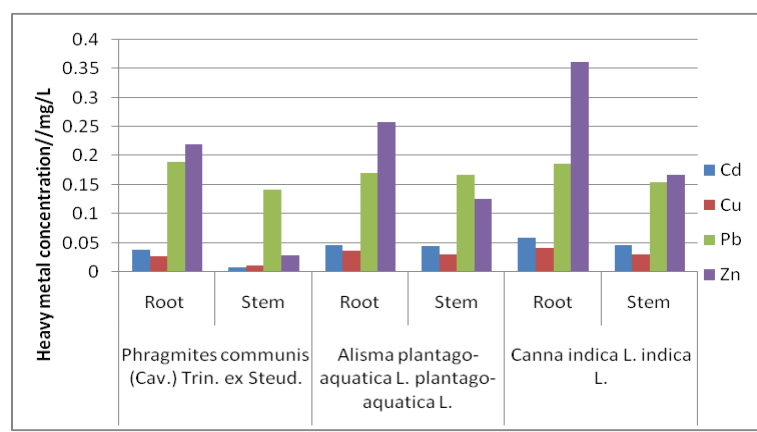

Figure 9 Total enrichment of heavy metals by aquatic plants (unit: $\mathrm{mg} / \mathrm{g}$ )

It can be seen from Table 9 that the total absorption of four heavy metals in plants is $\mathrm{Zn}>\mathrm{Pb}>\mathrm{Cd}>\mathrm{Cu}$; the total amount of $\mathrm{Cd}, \mathrm{Zn}$ and $\mathrm{Cu}$ absorbed by Canna indica $\mathrm{L}$. is twice more than the total amount of $\mathrm{Cd}, \mathrm{Zn}, \mathrm{Cu}$ and $\mathrm{zu}$ absorbed by Phragmites communis (Cav.); and the absorption of $\mathrm{Cd}$ and $\mathrm{Zn}$ by Alisma plantago-aquatica $\mathrm{L}$. is also significantly higher than that of Phragmites communis (Cav.).

It can be seen from Table 10 that the heavy metal content in the root is greater than that in the stem. The enrichment of four heavy metals $\mathrm{Cd}, \mathrm{Cu}, \mathrm{Pb}$ and $\mathrm{Zn}$ in the root of Phragmites communis (Cav.) is 5.41, 2.3, 1.3 and 7.9 times of the enrichment of four heavy metals in the stem. The enrichment effect of the root in Alisma plantago-aquatica $\mathrm{L}$. orientalis on heavy metals $\mathrm{Cd}, \mathrm{Cu}$, $\mathrm{Pb}$ and $\mathrm{Zn}$ is $1.05,1.18,1.02$ and 2.03 times of the four heavy metal enrichment effects of the stem. The enrichment effect of Canna indica L. root on heavy metals $\mathrm{Cd}, \mathrm{Cu}, \mathrm{Pb}$ and $\mathrm{Zn}$ was $1.28,1.3,1.2,2.16$ times of the four heavy metal enrichment effects of the stem.

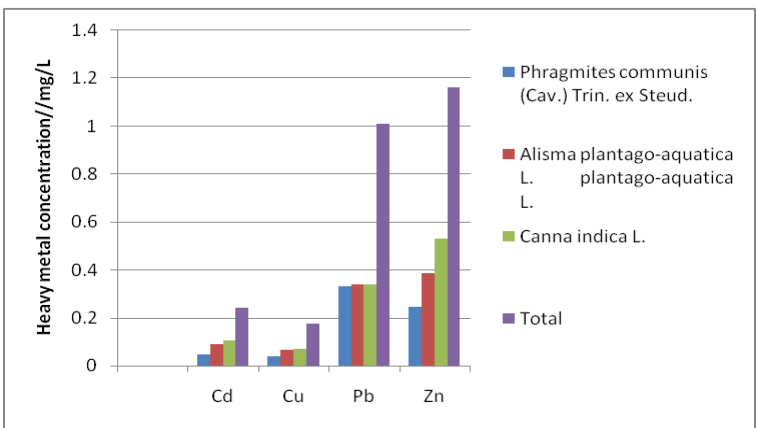

Figure 10 Enrichment of heavy metals in different parts of aquatic plants (unit: $\mathrm{mg} / \mathrm{g}$ )

The absorption effect of Phragmites communis (Cav.) (including roots and stems) on $\mathrm{Pd}$ is 7 times that of $\mathrm{Cd}$, 8.5 times that of $\mathrm{Cu}, 1.5$ times that of $\mathrm{Zn}$, so it is $\mathrm{Pb}>\mathrm{Zn}>\mathrm{Cu}>\mathrm{Cd}$, and $\mathrm{Zn}$ enrichment by Alisma plantago-aquatica $\mathrm{L}$. orientale. is about 4 times that of $\mathrm{Cd}$, 6 times that of $\mathrm{Cu}$, so it is $\mathrm{Zn}>\mathrm{Pb}>\mathrm{Cd}>\mathrm{Cu}$. The enrichment effect of Canna indica $\mathrm{L}$. on $\mathrm{Zn}$ is about 5 times that of $\mathrm{Cd}, 7.3$ times that of $\mathrm{Cu} 1.5$ times that of $\mathrm{Pb}$, so it is $\mathrm{Zn}>\mathrm{Pb}>\mathrm{Cd}>\mathrm{Cu}$.

The roots of Canna indica $\mathrm{L}$. indica have the highest enrichment of heavy metals of $\mathrm{Cd}, \mathrm{Cu}$ and $\mathrm{Zn}$, and the highest accumulation of heavy metals $\mathrm{Pb}$ is for the roots of Phragmites communis (Cav.). The enrichment of four heavy metals in the stem parts of plants can be seen the enrichment of heavy metals $\mathrm{Cd}, \mathrm{Cu}$ and $\mathrm{Zn}$ is the highest in Canna indica $\mathrm{L}$. and the highest enrichment of $\mathrm{Pb}$ is in the stem of Alisma plantago-aquatica L. orientale.

\subsubsection{Analysis of the absorption effect of aquatic plants on total nitrogen total phosphorus}

Table 11 Distribution of TN TP absorption by aquatic plants

unit: $\mathrm{mg} / \mathrm{g}$

\begin{tabular}{ccccccc}
\hline Variety & \multicolumn{2}{c}{$\begin{array}{c}\text { Phragmites communis } \\
\text { (Cav.) Trin. ex Steud. }\end{array}$} & \multicolumn{2}{c}{$\begin{array}{c}\text { Alisma plantago-aquatica L. } \\
\text { plantago-aquatica } \text { L. }\end{array}$} & \multicolumn{2}{c}{ Canna indica L. indica L. } \\
\cline { 2 - 7 } & Root & Stem & Root & Stem & Root & Stem \\
\hline TN & 0.1592 & 4.3007 & 5.873 & 2.578 & 2.1624 & 0.7987 \\
TP & 0.33 & 0.0175 & 0.0108 & 0.0021 & 0.0215 & 0.01 \\
\hline
\end{tabular}




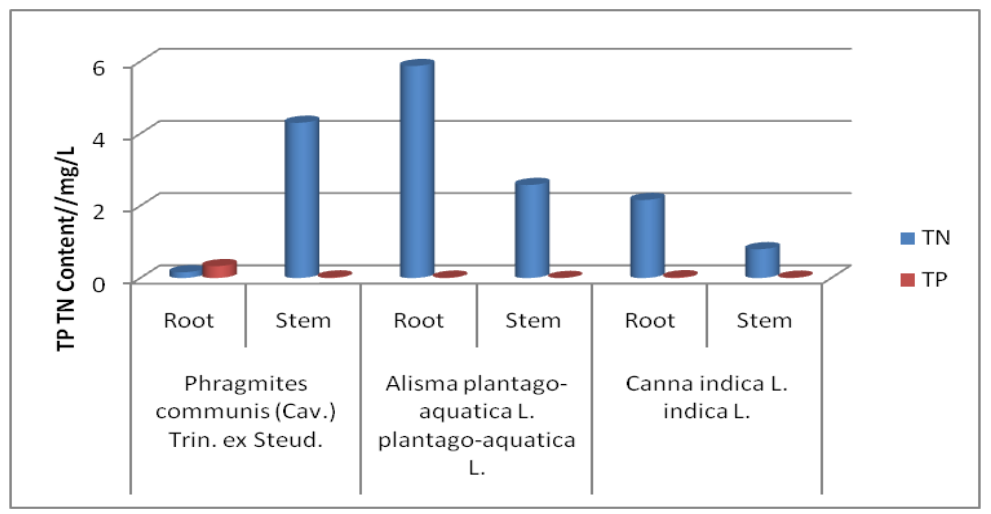

Figure 11 Distribution of TN TP absorption by aquatic plants unit: mg

It can be seen from table 11 that the absorption of TN by three plants (Phragmites communis (Cav.), Alisma plantago-aquatica L., Canna indica L.), and the absorption of TN by Alisma plantago-aquatica L. is twice that of Phragmites communis (Cav.)s and three times that of Canna indica L. The distribution of TN is also different in the same plant. The content of Phragmites communis (Cav.) root was $0.1592 \mathrm{mg} / \mathrm{g}$, which was much smaller than the content of $4.470 \mathrm{mg} / \mathrm{g}$ in the stem, while the TN content in the root of Alisma plantago-aquatica $\mathrm{L}$. orientalis was $5.873 \mathrm{mg} / \mathrm{g}$, which was greater than the content of $2.78 \mathrm{mg} / \mathrm{g}$ in the stem. The TN content in the root of Canna indica L. was $2.1624 \mathrm{mg}$. $/ \mathrm{g}$, greater than the stem content of $0.7987 \mathrm{mg} / \mathrm{g}$. Among them, the root of Alisma plantago-aquatica L. has the most TN content, and the least is the root of Phragmites communis (Cav.). The absorption of $\mathrm{TN}$ by the root of Phragmites communis (Cav.), Alisma plantago-aquatica L. orientale and Canna indica L. was 0.1592, 5.873 and 2.1624 respectively, so the root absorption of Alisma plantago-aquatica $\mathrm{L}$. orientalis was the largest. The absorption of $\mathrm{TN}$ by the stems of Phragmites communis (Cav.), Alisma plantago-aquatica L. orientale and Canna indica L. was 4.3007, 2.578 and 0.7987 respectively, so the stem absorption of Phragmites communis (Cav.) was the largest. Therefore, in the selected 3 plants, the best removal effect of $\mathrm{TN}$ in water is Alisma plantago-aquatica L., followed by Phragmites communis (Cav.) and Canna indica L.

It can be seen from Table 11 that the absorption of TP by three plants (Phragmites communis (Cav.), Alisma plantago-aquatica L., Canna indica L.) was obtained. The total absorption of TP by Phragmites communis (Cav.) was 0.3457 , which was the largest among the three plants, 30 times that of Alisma plantago-aquatica L. and Ten times of Canna indica L. The TP distribution of each part of the three plants can be analyzed as the following: The TP content of the Phragmites communis (Cav.) root is the largest, and the content of the Alisma plantago-aquatica L. stem is the least. Comparing the absorption contents of the three plant roots, the TP content in the roots of the Phragmites communis (Cav.)s was the highest, and the distribution in the roots of the Alisma plantago-aquatica
L. was the lowest. From the comparison of the stems of the three plants it was the highest in the stems of the Phragmites communis (Cav.)s and the lowest in the stems of the Alisma plantago-aquatica L. The distribution of TP is also different in the same plant. For example, the roots and stems of Phragmites communis (Cav.)s are distributed by 0.33 and 0.0175 respectively, which is about 30 times in difference. Therefore, based on the analysis of the total absorption of $\mathrm{TP}$ and the parts of plants of the above three plants, the effect of Phragmites communis (Cav.) on the removal of TP was the best.

\section{Conclusion}

Through the analysis of the data detection on water and aquatic plants, the following conclusions can be drawn:

(1) After the treatment of the artificial wetland, TP, $\mathrm{TN}, \mathrm{COD}$ and NH3-N in river are significantly lower than those in untreated, indicating that the artificial wetland has a good purification effect on these water quality indicators;

(2) From the perspective of different wetland types, the artificial subsurface wetland has the best effect in removing TP, TN, COD, NH3-N and other factors, and the artificial surface wetland effect is second; from the perspective of the artificial wetland on the pollution factor in different seasons, the removal effect is as follows: In the removal of TP and TN factors, it is wet season $>$ normal season $>$ dry season; in the removal of the NH3-N and COD factors, it is normal season $>$ dry season $>$ wet season. In addition to the $\mathrm{TN}$ factor, we can also conclude from the experimental data that the water quality in dry season and normal season is significantly better than the water quality in wet season. This is because the water quality level changes greatly during wet season, and it is unstable. Usually, the abundant rainfall results in poor water quality. However, due to its large water capacity and plant growing season, the efficiency of removing TP and TN factors is high during wet season.

(3) Through the analysis of the total amount of heavy metals absorbed by three plants such as Phragmites communis (Cav.), Alisma plantago-aquatica L., Canna 
indica L., it can be concluded that Canna indica L. is most suitable as a plant for treating heavy metals in domestic sewage. The heavy metal content in plant roots is larger than that in stem; The best removal effect of TN in water is Alisma plantago-aquatica L., followed by Phragmites communis (Cav.) and Canna indica L.; Phragmites communis (Cav.)s have much better TP removal effect than Alisma plantago-aquatica L. and Canna indica L.; Aquatic plants can not only absorb organicsm, nitrogen, phosphorus and other nutrients in the artificial wetland system, but also provide a place for micro-organisms to be attached, so that pollutants can be removed by nitrification, denitrification, adsorption, etc., especially the tall trees ( Such as Chisui, Metasequoia, etc.). After entering the artificial wetland, the sewage is in contact with the biofilm grown in the roots of the plants during the flow process, and is purified by physical, chemical and biological effects. The artificial wetland has the advantages of simple operation and low operating cost, but it also has the disadvantages of occupying a large area, a small hydraulic load, and limited purification capacity.

\section{Acknowledgement}

Funded by Major Education and Research Project of Anhui Provincial Education Department (2016jyxm0967), Anhui University Student Innovation and Entrepreneurship Project (201710375020, AH201610375041) and the high-level teaching team of Anhui Province (2018jxtd149)

Funded by the Key Research and Development Project of Anhui Province--The Application and Demonstration of New Technology for Cultivation of Zhulan Flower (201904a06020033)

\section{References}

1. Ruan Jiajin, Liu Ping, Liu Xiaonan, et al. Treatment Effects of Three Types of Artificial Wetlands in Non-point Source Pollution[J]. Environmental Engineering, 2015, 33(9): 16-19.

2. Liu Lifeng, Su Hui, Li Fengjuan, et al. Research Progress in Ammonia Nitrogen Wastewater Treatment Technology [J]. Industrial Water Treatment, 2014, (I1): 13-17.

3. Liu Ying, Liu Xiaohui, Zhang Yaru, et al. Adsorption Characteristics of Three Artificial Wetland Fillers for Low Concentration Ammonia Nitrogen Wastewater [J]. Environmental Chemistry, 2018,37(5): 1118-1127.

4. Lu Wei, Yan Guisheng, Wang Huan. Experimental Study on Treatment of Low Concentration Ammonia Nitrogen Wastewater $[\mathrm{J}]$. Chemical Intermediate, 2013,10(1):42-46.

5. Zhang Zehua, Feng Chongling, Wu Xiaofu, et al. Research Progress on Filler and Purification Mechanism of Artificial Wetland Sewage Treatment System[J]. Journal of Ecology, 2016, 35 (8): $2234-2243$.
6. Du Gang, Huang Lei, Gao Xu, et al. Relationship Between Microbial Quantity and Pollutant Removal in Artificial Wetlands [J]. Wetland Science, 2013, 11(1): 13-20.

7. WANG X, TIAN Y, ZHAO X, et al. Effects of aeration position on organics, nitrogen and phospho rus removal in combined oxidation pond-artificial wetland systems [J]. Bioresource Technology, 2015, 198: 7.

8. FANG Z, SONG HL, NING C, et al. Electricity production from azo dye wastewater using a micr obial fuel coupled artificial wetland operating under different operating conditions[J]. Biosensor s\&Bioelectronic, 2015, 68 (68):135-141 .

9. Ding Yi, Wang Rui, Wang Yuhui, Song Xinshan. Study on the mechanism of nitrogen removal and its influencing factors in horizontal subsurface flow artificial wetland[J]. Industrial Water Treatment, 2015, 35 (06): 6-10.

10. Shi Yunpeng, Zhou Qi. Research progress on kinetic model of pollutant removal from artificial wetlands $[\mathrm{J}]$. Industrial Water \& Wastewater, 2015, 6 (33):12-14.

11. QIAN Mingfei, LI Yong, HUANG Yong. Comparison of the effect of Phragmites communis (Cav.) and cattail artificial wetland system on purifying micro-polluted river water $[\mathrm{J}]$. Industrial Water \& Wastewater, 2008, 39 (06):55-58. 